\title{
MOLECULAR CLONING, RECOMBINANT EXPRESSION AND \\ FUNCTIONAL CHARACTERIZATION OF A NOVEL ISOFORM OF ANTI-LIPOPOLYSACCHARIDE FACTOR FROM THE CRUCIFIX
}

\section{CRAB, CHARYBDIS FERIATUS}

\author{
Sruthy K S ${ }^{1^{*}}$, Aishwarya Nair ${ }^{1^{*}}$, Jayesh $\mathbf{P}^{1^{*}}$, I S Bright Singh ${ }^{2 *}$ and Rosamma Philip ${ }^{1_{\S}}$ \\ ${ }^{1}$ Department of Marine Biology, Microbiology and Biochemistry, School of Marine Sciences, \\ Cochin University of Science and Technology, Fine Arts Avenue, Kochi-682016, Kerala, \\ India
}

${ }^{2}$ National Centre for Aquatic Animal Health, Cochin University of Science and Technology, Kochi-16, Kerala, India

\begin{abstract}
Anti-lipopolysaccharide factor (ALF), one of the key effector molecules in innate immune system of crustaceans is a cationic Antimicrobial Peptide (AMP) having broad spectrum antibacterial and antiviral property. In the present study we identified and characterized one isoform of ALF homolog (Cf-ALF2) from the haemocytes of crucifix crab, Charybdis feriatus. The partial cDNA of 294bp encoded for a mature peptide with 98 amino acid constituting a molecular mass of $10.923 \mathrm{kDa}$ with a net charge of +9 and $\mathrm{p} I$ of 10.09. Furthermore, different from the previously identified ALF isoforms, Cf-ALF2 has a LPS binding domain with 23 amino acids including two cysteines instead of 22 amino acids and also exhibited less sequence similarity. Secondary structure of Cf-ALF2 predicted using PSIPRED constitutes two alpha helices packed against three beta strands. Multiple alignment performed for Cf-ALF2 with representatives of ALFs from limulids and decapod crustaceans using MEGA 6.0 revealed the existence of conserved regions within the sequence. The recombinant form of Cf-ALF2 (rCf-ALF2) was expressed as a fusion protein in E. coli, Rosettagami B DE3 pLysS using the pET-32a+ vector. The purified and refolded rCf-ALF2 protein revealed antimicrobial activity even
\end{abstract}


at $2.5 \mu \mathrm{M}$ against Gram-negative bacteria viz., Pseudomonas aeruginosa, Aeromonas hydrophila and Edwardsiella tarda and Gram-positive bacteria viz., Bacillus cereus and Staphylococcus aureus. Recombinant Cf-ALF2 was found to be non-haemolytic and non-cytotoxic even at a concentration of $8 \mu \mathrm{M}(250 \mu \mathrm{g} / \mathrm{mL})$. These preliminary functional studies strongly suggest that Cf-ALF2 is a potent AMP against bacterial infection and might function as a promising therapeutic candidate in aquaculture and medicine.

Keywords: Antimicrobial peptides; Crab; Innate Immunity; Recombinant Expression; Antilipopolysaccharide factor.

*These authors have contributed equally to this work.

${ }^{\S}$ Corresponding author. Tel: + 914842368120, Fax: $\quad+914842381120$

E-mail address: rosammap@gmail.com 